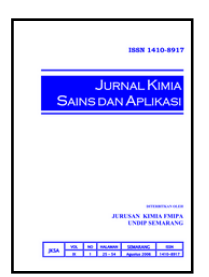

\title{
Isolasi dan Identifikasi Senyawa Aktif dari Ekstrak Aseton Rimpang Bangle (Zingiber cassumunar Roxb.) sebagai Antioksidan
}

\author{
Ika Rissanti ${ }^{a}$, Enny Fachriyah ${ }^{a^{*}}$, Dewi Kusrini $^{a}$ \\ a Organic Chemistry Laboratory, Chemistry Department, Faculty of Sciences and Mathematics, Diponegoro University, Jalan Prof. \\ Soedarto, Tembalang, Semarang \\ * Corresponding author: dewi.kusrini@live.undip.ac.id
}

\begin{tabular}{l} 
Article Info \\
\hline \\
\hline Keywords: \\
Bangle (Zingiber \\
cassumunar Roxb.), \\
Isolation, \\
Identification, \\
antioxidants, DPPH
\end{tabular}

Kata Kunci:

Bangle (Zingiber cassumunar Roxb.), Isolasi, Identifikasi, Antioksidan, DPPH

\begin{abstract}
An active compound was isolated and identified from acetone extracts of bangle rhizome (Zingiber cassumunar Roxb.) as an antioxidant. Isolation of active compounds was done by soxhlet and chromatography method while antioxidant assay by DPPH method. The active isolate was analyzed using UV-Vis spectrophotometer by the addition of some shift reagent and FTIR. Based on the analysis results, the active isolate was suspected as auron from flavonoid class that has absorbance at wavelength $260.5 \mathrm{~nm}$ (band II) and $421.5 \mathrm{~nm}$ (band I), it has hydroxylation pattern on $6,7,3^{\prime}, 4^{\prime}$, and contains a functional group of $\mathrm{OH}, \mathrm{CO}$ phenols, $\mathrm{CO}$ ether, $\mathrm{C}=\mathrm{O}$ ketone, $\mathrm{C}=\mathrm{C}$ alkene, $\mathrm{C}=\mathrm{C}$ and $=\mathrm{CH}$ aromatics, and substituted benzene, that was suspected as $6,7,3^{\prime}, 4^{\prime}$ tetrahidroksiauron (Maritimetin) compound. Antioxidant assay of the acetone extracts showed $\mathrm{IC}_{50}$ at 91.513 ppm thus classified as a strong antioxidant.
\end{abstract}

\section{Abstrak}

Telah dilakukan isolasi dan identifikasi senyawa aktif ekstrak aseton rimpang bangle (Zingiber cassumunar Roxb.) sebagai antioksidan. Isolasi senyawa aktif dilakukan dengan ekstraksi soklet dan kromatografi sedangkan uji aktivitas antioksidan dilakukan dengan metode DPPH. Isolat aktif dianalisis menggunakan spektrofotometer UV-Vis dan pereaksi geser serta FTIR. Berdasarkan hasil analisis tersebut diduga bahwa isolat aktif adalah senyawa flavonoid golongan auron yang memiliki serapan pada panjang gelombang 260,5 nm (pita II) dan $421,5 \mathrm{~nm}$ (pita I), memiliki pola hidroksilasi pada $6,7,3^{\prime}, 4^{\prime}$, dan mengandung gugus fungsi $\mathrm{OH}, \mathrm{CO}$ fenol, $\mathrm{CO}$ eter, $\mathrm{C}=\mathrm{O}$ keton, $\mathrm{C}=\mathrm{C}$ alkena, $\mathrm{C}=\mathrm{C}$ dan $=\mathrm{CH}$ aromatik, serta benzena tersubstitusi sehingga diduga sebagai senyawa $6,7,3^{\prime}, 4^{\prime}$ tetrahidroksiauron (Maritimetin). Uji aktivitas antioksidan terhadap ekstrak aseton menunjukkan harga $\mathrm{IC}_{50}$ sebesar $91,513 \mathrm{ppm}$ sehingga tergolong sebagai antioksidan kuat.

\section{Pendahuluan}

Salah satu dari penyakit degeneratif yang banyak terjadi pada beberapa dekade ini adalah kanker yang disebabkan karena antioksidan dalam tubuh tidak mampu menetralisir peningkatan konsentrasi radikal bebas. Antioksidan merupakan suatu senyawa yang dapat menghambat atau mencegah proses oksidasi senyawa lain yang diakibatkan oleh adanya suatu radikal bebas [1]. Radikal bebas adalah atom atau molekul yang mempunyai satu atau lebih elektron yang tidak berpasangan sehingga bersifat sangat reaktif [2].

Bangle (Zingiber cassumunar Roxb.) merupakan tanaman dalam famili Zingiberaceae dan mengandung beberapa senyawa kimia meliputi Phlobatanin, flavonoid, alkaloid, saponin, tannin, terpenoid, steroid, dan glikosida [3] sehingga dapat digunakan sebagai obat untuk mencegah peradangan (sebagai antiinflamasi), mengobati asma, memiliki efek karminatif [4], 
antibakteri [5], antiobesitas [6], antialergi [7], dan bersifat sebagai antioksidan [8].

Beberapa penelitian tentang rimpang bangle telah dilakukan diantaranya adalah ditemukannya senyawa jenis phenilbutenoid seperti [(E)-4-(3',4'dimethoxyphenyl)but-3-en-1-ol ], [(E)-4-(2', ', ,' trimethoxyphenyl)- but-3-en-1-ol] dan [(E)-4(3',4',1-trimethoxy- phenyl)but-3-en-1-ol] dalam ekstrak etil asetat rimpang bangle sebagai imunostimulan [9], identifikasi senyawa kaemferol-3o-metileter pada ekstrak metanol rimpang bangle sebagai antioksidan, serta uji aktivitas ekstrak diklorometan dan ekstrak metanol dari rimpang bangle sebagai antioksidan [8].

Sumber antioksidan yang potensial telah banyak ditemukan berasal dari tumbuhan dan perlu dieksplorasi lebih lanjut untuk mendapatkan alternatif senyawa penangkap radikal yang aman beraktivitas besar. Oleh karena itu penelitian ini bertujuan untuk mengisolasi dan mengidentifikasi senyawa aktif ekstrak aseton rimpang bangle yang memiliki ativitas sebagai antioksidan.

\section{Metode Penelitian}

Alat dan Bahan

Alat gelas standar penelitian, timbangan digital, satu set alat soklet, water bath, maserator, rotary evaporator, satu set KLT dan kromatografi kolom, lampu UV, Spektrofotometer UV-Vis dan FTIR. Rimpang bangle, n-heksana, aseton, kloroform aquades, aseton, metanol, etanol, butanol, benzena, diklorometana, etil asetat, dan asam asetat, silika gel, serbuk $\mathrm{Mg}$, amil alkohol, $\mathrm{HCl}$ pekat, $\mathrm{FeCl}_{3}, \mathrm{NaOH}$, ammonia, pereaksi Dragendroff $\left(\mathrm{Bi}^{3+}\right.$ dan $\left.\mathrm{HI}\right)$, pereaksi Mayer $\left(\mathrm{Hg}^{2+}\right.$ dan $\left.\mathrm{KI}\right)$, eter, anhidrida asam asetat, $\mathrm{H}_{2} \mathrm{SO}_{4}, \mathrm{AlCl}_{3}, \mathrm{NaOAc}, \mathrm{H}_{3} \mathrm{BO}_{3}$, DPPH, kuersetin.

\section{Isolasi Senyawa Aktif}

Serbuk rimpang bangle diekstraksi dengan cara soklet menggunakan n-heksana pada suhu $70^{\circ} \mathrm{C}$. Residu n-heksana diangin-anginkan dan disoklet kembali dengan aseton sehingga diperoleh ekstrak aseton. Ekstrak aseton diuji fitokimia (alkaloid, flavonoid, steroid, terpenoid, tannin, dan saponin) dan aktivitas antioksidannya dengan metode DPPH.

Ekstrak aseton yang mengandung senyawa aktif dilakukan KLT dan dipisahkan dengan kromatografi kolom sehingga diperoleh 5 fraksi besar. Masingmasing fraksi hasil kromatografi kolom diuji aktivitas antioksidannya. Fraksi yang memilik aktivitas antioksidan terkuat dipisahkan dengan KLT preparatif sehingga diperoleh isolat aktif. Isolat aktif diuji kemurniannya dengan KLT berbagai eluen dan KLT dua dimensi.

Uji aktivitas antioksidan

Uji aktivitas antioksidan dilakukan dengan metode DPPH (1,1-difenil-2-pikrilhidrazil)
Uji Kualitatif antioksidan

Plat KLT yang telah digunakan untuk memisahkan senyawa disemprot dengan larutan DPPH 0,1 mM yang dibuat dengan melarutkan $1 \mathrm{mg}$ serbuk DPPH ke dalam $25 \mathrm{~mL}$ metanol. Aktivitas antioksidan ditunjukkan dengan warna kuning berlatar belakang ungu pada plat KLT.

\section{Uji Kuantitatif antioksidan}

Sebanyak 0,002 g ekstrak aseton rimpang bangle dilarutkan dalam $10 \mathrm{~mL}$ metanol sehingga diperoleh larutan ekstrak dengan konsentrasi 200 ppm sebagai larutan induk. Larutan ekstrak 200 ppm diencerkan menjadi berbagai konsentrasi (0, 20, 40, 60, 80, 100 ppm) dan masing-masing direaksikan dengan larutan DPPH 0,1 mM selama 30 menit. Pengukuran absorbansi dilakukan pada panjang gelombang $517 \mathrm{~nm}$ dengan kuersetin sebagai pembanding. Perhitungan aktivitas antioksidan ditentukan menggunakan persamaan berikut:

$$
\% \text { inhibisi }=\frac{A \text { blanko }-A \text { sampel }}{A \text { blanko }} \times 100 \%
$$

Keterangan:

A blanko = absorbansi DPPH dalam etanol

A sampel = absorbansi DPPH dalam sampel

Nilai $\mathrm{IC}_{50}$ dihitung menggunakan rumus persamaan regresi.

\section{Identifikasi Senyawa Aktif}

Isolat aktif dianalisis dan diidentifikasi strukturnya menggunakan spektrofotometer UV-Vis dan pereaksi geser serta FTIR.

\section{Hasil Dan Pembahasan}

Isolasi senyawa aktif

Sebanyak $1070 \mathrm{~g}$ serbuk rimpang bangle diekstraksi dengan cara soklet menggunakan pelarut n-heksana pada suhu $70^{\circ} \mathrm{C}$ untuk menghilangkan senyawasenyawa yang bersifat non polar seperti lemak, steroid, dan triterpenoid. Proses ekstraksi dengan cara soklet dipilih karena penyarian terjadi berulang-ulang sehingga zat yang tersari di dalam pelarut lebih banyak dengan penggunaan pelarut yang sedikit. Residu yang diperoleh disoklet kembali dengan aseton sehingga diperoleh ekstrak aseton yang selanjutnya dilakukan uji fitokimia sehingga diketahui kandungan senyawa kimia di dalamnya.

Ekstrak aseton diuji aktivitas antioksidannya dengan metode DPPH (1,1-difenil-2-pikrilhidrazil) secara kualitatif dan kuantitatif. Pengujian antioksidan secara kualitatif dilakukan menggunakan KLT dengan eluen kloroform:aseton (10:1) dan memberikan hasil positif dengan terbentuknya warna kuning berlatar belakang ungu pada plat KLT. Perubahan warna terjadi karena reaksi antara radikal DPPH (1,1-difenil-2pikrilhidrazil) dengan senyawa antioksidan yang terdapat pada ekstrak aseton membentuk senyawa 1,1difenil-2-pikrilhidrazin yang berwarna kuning. 


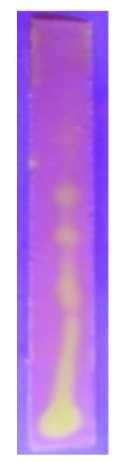

(a)

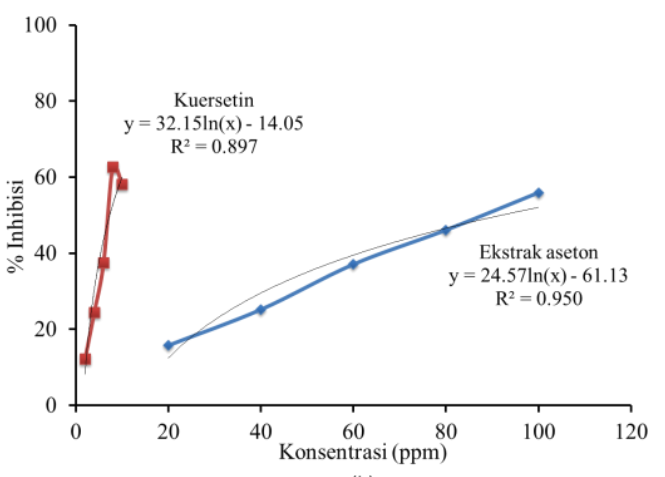

(b)
Gambar 1. (a) Hasil uji antioksidan kualitatif ekstrak aseton dan (b) grafik hasil pengukuran antioksidan ekstrak aseton dan kuersetin

Hasil pengukuran aktivitas antioksidan ekstrak aseton secara kuantitatif dilakukan menggunakan spektrofotometer UV-Vis dengan pembanding senyawa kuersetin yang telah diketahui sebagai antioksidan. Aktivitas antioksidan secara kuantitatif dinyatakan dengan nilai $\mathrm{IC}_{50}$ yang ditentukan melalui persamaan regresi pada grafik hubungan antara daya antioksidan (\%) serapan radikal DPPH dengan konsentrasi larutan ekstrak aseton. Grafik hasil pengukuran hubungan antara \% inhibisi dan konsentrasi larutan uji ditunjukkan pada gambar 1.

Berdasarkan persamaan regresi linear pada grafik tersebut dapat diketahui harga $\mathrm{IC}_{50}$ ekstrak aseton adalah 91,513 ppm. Hal ini menunjukkan bahwa ekstrak aseton memiliki aktivitas antioksidan yang kuat karena memiliki harga $\mathrm{IC}_{50}$ kurang dari 200 ppm [10]. Apabila dibandingkan dengan kuersetin maka aktivitas antioksidan ekstrak aseton 11,210 kali lebih rendah dari kuersetin yang memiliki harga $\mathrm{IC}_{50}$ sebesar $8,163 \mathrm{ppm}$. Hal ini dikarenakan senyawa dalam ekstrak aseton yang berperan sebagai antioksidan belum murni sehingga memiliki aktivitas antioksidan yang rendah dibandingkan dengan senyawa kuersetin.

Ekstrak aseton yang telah diketahui aktivitas antioksidannya dianalisis mengguna- kan KLT dengan eluen kloroform:aseton (10:1) yang ditunjukkan pada gambar 2.

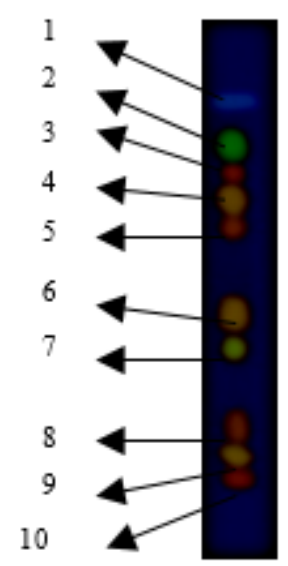

Pola noda yang terlihat menunjukkan pemisahan yang cukup baik sehingga eluen kloroform:aseton (10:1) dapat digunakan untuk pemisahan skala besar menggunakan kromatografi kolom. Diperoleh 5 fraksi besar hasil pemisahan dengan kromatografi kolom yaitu fraksi A,B,C,D, dan E.

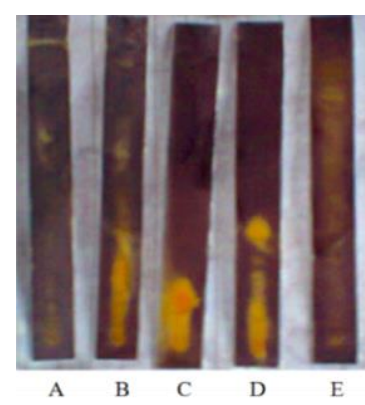

(a)

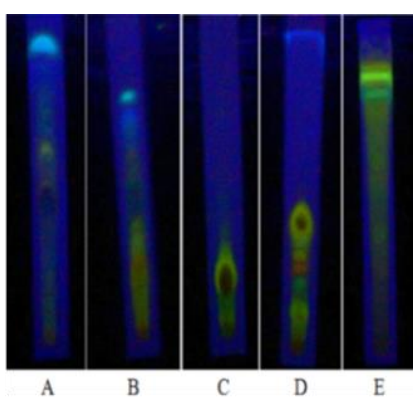

(b)
Gambar 3. Hasil pengujian antioksidan masing-masing fraksi secara kualitatif (a) pada sinar tampak dan (b) pada sinar UV $\lambda 365 \mathrm{~nm}$

Hasil pengujian antioksidan secara kualitatif pada masing-masing fraksi menunjukkan bahwa pada fraksi D memiliki aktivitas antioksidan terkuat. Selanjutnya fraksi D dipisahkan menggunakan KLT preparatif sehingga diperoleh isolat murni yang kemudian diuji kemurniannya dengan KLT berbagai eluen dan KLT dua dimensi. Hasil uji kemurnian menggunakan KLT berbagai eluen dan KLT dua dimensi terhadap isolat ditunjukkan pada gambar 4 .

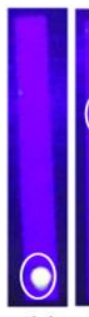

(a)

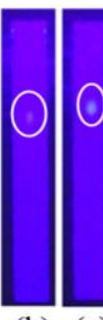

(b) (c)

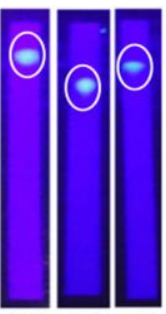

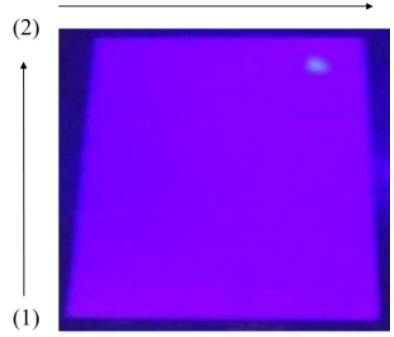

(b)
Gambar 4. (a) Hasil uji kemurnian isolat dengan KLT berbagai eluen dan (b) KLT dua dimensi pada UV $\lambda 365$ $\mathrm{nm}$

Hasil uji kemurnian menggunakan KLT berbagai eluen dan KLT dua dimensi terhadap isolat masingmasing menghasilkan satu noda pada setiap pengujian. Hal ini menunjukkan bahwa isolat diduga telah murni.

\section{Identifikasi Senyawa Aktif}

Hasil analisis spektrofotometri UV-Vis terhadap isolat aktif menunjukkan adanya dua serapan panjang gelombang yaitu pada $421,5 \mathrm{~nm}$ (pita I) dan $260,5 \mathrm{~nm}$ (pita II) yang menunjukkan senyawa flavonoid golongan auron. Spektrum UV-Vis isolat (dalam metanol) ditunjukkan pada gambar 5 . 


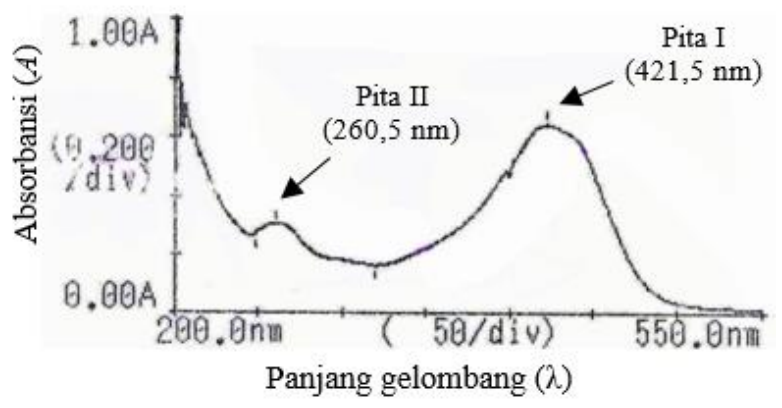

Gambar 5. Spektrum UV-Vis isolat (dalam metanol)

Struktur senyawa flavonoid dan pola oksigenasinya dapat ditentukan dengan menambahkan pereaksi geser pada isolat. Hal ini dikarenakan pereaksi geser dapat bereaksi dengan gugus hidroksil pada flavonoid sehingga dapat digunakan untuk meramalkan posisi gugus hidroksil pada struktur flavonoid berdasarkan pergeseran panjang gelombang yang terjadi [11]. Pereaksi geser yang digunakan meliputi natrium hidroksida $(\mathrm{NaOH})$, alumunium klorida $\left(\mathrm{AlCl}_{3}\right)$, asam klorida $(\mathrm{HCl})$, natrium asetat ( $\mathrm{NaOAc})$, dan asam borat $\left(\mathrm{H}_{3} \mathrm{BO}_{3}\right)$. Hasil pengukuran spektra UV-Vis terhadap isolat dengan penambahan pereaksi geser tersebut ditunjukkan pada gambar 6 .

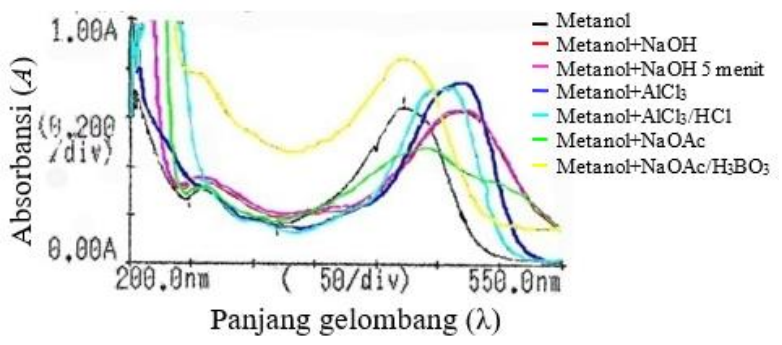

Gambar 6. Spektrum UV-Vis isolat (dalam metanol) dengan penambahan pereaksi geser

Pergeseran panjang gelombang isolat dengan penambahan pereaksi geser $\mathrm{NaOH}, \mathrm{AlCl}_{3}, \mathrm{HCl}, \mathrm{NaOAc}$, dan $\mathrm{H}_{3} \mathrm{BO}_{3}$ ditunjukkan pada tabel 1 .

Tabel 1: Hasil pengukuran spektra UV-Vis isolat

\begin{tabular}{|c|c|c|c|c|}
\hline Pereaksi & $\begin{array}{l}\text { Pita I } \\
(\mathrm{nm})\end{array}$ & $\begin{array}{l}\text { Pita II } \\
(\mathrm{nm})\end{array}$ & $\begin{array}{l}\text { Pergeseran } \\
\text { Pita I (nm) }\end{array}$ & Keterangan \\
\hline Metanol & 421,5 & 260,5 & - & $\begin{array}{c}\text { Flavonoid golongan } \\
\text { Auron }\end{array}$ \\
\hline $\mathrm{NaOH}$ & 468,0 & 257,5 & 46,5 & $\begin{array}{c}\text { 6-OH dengan } \\
\text { oksigenasi pada 4' }\end{array}$ \\
\hline $\begin{array}{l}\mathrm{NaOH} 5 \\
\text { menit }\end{array}$ & 469,0 & 257,0 & 47,5 & $\begin{array}{c}\text { 6-OH dengan } \\
\text { oksigenasi pada 4' }\end{array}$ \\
\hline $\mathrm{NaOAc}$ & 441,0 & 260,0 & 19,5 & $\begin{array}{l}\text { Gugus hidroksi pada } \\
4^{\prime} \text { dan } 6-\mathrm{OH} \text { pada } \\
\text { cincin } \mathrm{A}\end{array}$ \\
\hline $\begin{array}{l}\mathrm{NaOAc} \\
+\mathrm{H}_{3} \mathrm{BO}_{3}\end{array}$ & 422,5 & - & 1 & $\begin{array}{l}\text { Ortodihidroksi pada } \\
\text { cincin } \mathrm{A}\left(\mathrm{C}_{6} \text { dan } \mathrm{C}_{7}\right)\end{array}$ \\
\hline $\mathrm{AlCl}_{3}$ & 471 & - & 49,5 & $\begin{array}{l}\text { Orthodihidroksi pada } \\
\text { cincin B }\end{array}$ \\
\hline $\begin{array}{l}\mathrm{AlCl}_{3}+ \\
\mathrm{HCl}\end{array}$ & 448 & 232 & 42 & $\begin{array}{l}\text { Orthodihidroksi pada } \\
\text { cincin B }\end{array}$ \\
\hline
\end{tabular}

Berdasarkan data dan analisis di atas maka dapat diduga bahwa isolat aktif adalah senyawa jenis $6,7,3^{\prime}, 4^{\prime}$-tetrahidroksiauron (maritimetin). Struktur senyawa maritimetin ditunjukkan pada gambar 7 .<smiles>O=C1C(=Cc2ccc(O)c(O)c2)Oc2c1ccc(O)c2O</smiles>

Gambar 7. Struktur senyawa 6,7,3'4'-tetrahidroksiauron (maritimetin)

Identifikasi senyawa maritimetin selanjutnya dilakukan dengan spektrofoto- meter FTIR untuk memperkuat dugaan hasil identifikasi dengan spektrofotometer UV-Vis. Hasil analisis FTIR senyawa maritimetin ditunjukkan pada gambar 8 .

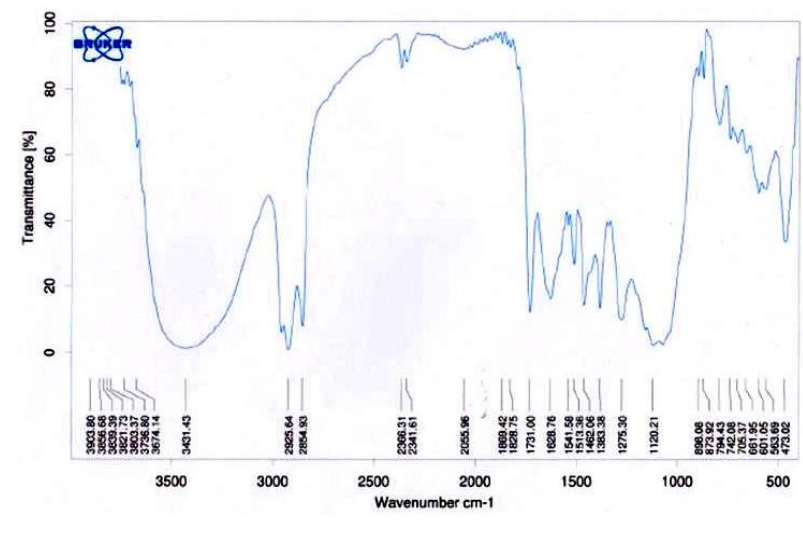

Gambar 8. Spektrum FTIR isolat

Serapan bilangan gelombang hasil analisis FTIR terhadap senyawa maritimetin ditunjukkan pada tabel 2 .

Tabel 2: Pita serapan FTIR isolat

\begin{tabular}{cc}
\hline $\begin{array}{c}\text { Bilangan } \\
\text { Gelombang }\left(\mathrm{cm}^{-1}\right)\end{array}$ & Gugus Fungsi \\
\hline 3431,43 & $\begin{array}{c}\text { O-H ulur yang dapat } \\
\text { membentuk ikatan hidrogen } \\
\text { =C-H ulur aromatik }\end{array}$ \\
2925,00 & $\mathrm{C}-\mathrm{H}$ ulur (asimetri) \\
2854,93 & $\mathrm{C}-\mathrm{H}$ ulur (simetri) \\
1731,00 & $\mathrm{C}=\mathrm{O}$ ulur keton \\
1628,76 & $\mathrm{C}=\mathrm{C}$ ulur (alkena konjugasi) \\
1513,$36 ; 1541,58$ & $\mathrm{C}=\mathrm{C}$ ulur (aromatik) \\
1462,06 & $\mathrm{C}-\mathrm{H}$ tekuk \\
1383,38 & O-H tekuk bidang \\
1275,30 & $\mathrm{C}-\mathrm{O}$ eter (jembatan O) \\
1120,21 & $\mathrm{C}-\mathrm{O}$ ulur fenol \\
873,$92 ; 794,43 ;$ & Benzena tersubstitusi meta, \\
742,08 & para dan ortho \\
\hline
\end{tabular}

Hasil analisis dengan spektrofotometer FTIR menunjukkan adanya gugus $\mathrm{OH}, \mathrm{CO}$ fenol, $\mathrm{CO}$ eter, $\mathrm{C}=\mathrm{O}$ keton, $\mathrm{C}=\mathrm{C}$ alkena, $\mathrm{C}=\mathrm{C}$ dan $=\mathrm{CH}$ aromatik, serta benzena tersubstitusi. Gugus fungsi hasil analisis FTIR sesuai 
dengan gugus fungsi pada senyawa 6,7,3',4'tetrahidroksiauron (maritimetin) hasil analisis menggunakan spektrofotometer UV-Vis dan pereaksi geser. Dengan demikian dapat disimpulkan bahwa senyawa maritimetin merupakan salah satu senyawa yang terkandung dalam ekstrak aseton rimpang bangle dan memiliki aktivitas antioksidan. Harga $\mathrm{IC}_{50}$ senyawa maritimetin diduga lebih rendah dari IC $_{50}$ ekstrak aseton rimpang bangle (91,513 ppm). Hal ini dikarenakan maritimetin merupakan senyawa murni sehingga memiliki aktivitas antioksidan yang lebih kuat. Mekanisme reaksi antara DPPH dengan senyawa maritimetin hasil isolasi dari ekstrak aseton rimpang bangle (Zingiber cassumunar Roxb.) ditunjukkan pada gambar 9 .

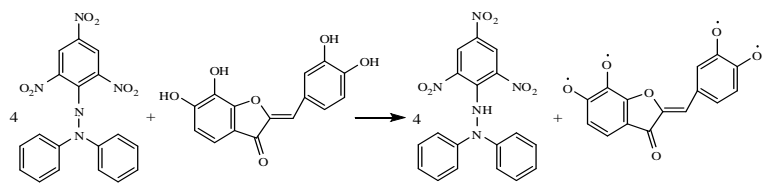

Gambar 9. Reaksi antara DPPH senyawa maritimetin hasil isolasi dari ekstrak aseton rimpang bangle (Zingiber cassumunar Roxb.)

\section{Kesimpulan}

Ekstrak aseton rimpang bangle memiliki aktivitas antioksidan yang kuat dengan harga $\mathrm{IC}_{50}$ sebesar 91,513 ppm. Senyawa aktif dalam ekstrak aseton rimpang bangle yang memiliki aktivitas sebagai antioksidan adalah senyawa flavonoid berupa padatan berwarna kuning. Hasil identifikasi isolat menggunakan spektrofotometer UV-Vis dengan pereaksi geser dan FTIR menunjukkan bahwa isolat tersebut diduga sebagai senyawa 6,7,3',4' -tetrahidroksiauron (maritimetin).

\section{Daftar Pustaka}

[1] Titik Sunarni, Suwidjiyo Pramono, Ratna Asmah, Flavonoid antioksidan penangkap radikal dari daun kepel (Stelechocarpus burahol (Bl.) Hook f. \& Th.), Majalah Farmasi Indonesia, 18, 3, (2007) 111-116

[2] RJ Fessenden, JS Fessenden, Kimia Organik, 3rd edition ed., A. Pudjaatmaka, 1989.

[3] S Majaw, J Moirangthem, Qualitative and quantitative Analysis of Clerodendron colebrookianum walp. leaves and Zingiber cassumunar Roxb. Rhizomes, Ethnobotanical Leaflets, 2009, 5, (2009) 3

[4] Mohammad Nazrul Islam Bhuiyan, Jasim Uddin Chowdhury, Jaripa Begum, Volatile constituents of essential oils isolated from leaf and rhizome of Zingiber cassumunar Roxb, Bangladesh Journal of $\begin{array}{llll}\text { Pharmacology, } \quad 3, \quad 2, \quad \text { (2008) } & 69-73\end{array}$ http://dx.doi.org/10.3329/bjp.v3i2.844

[5] Tg Siti Amirah Tg Kamazeri, Othman Abd Samah, Muhammad Taher, Deny Susanti, Haitham Qaralleh, Antimicrobial activity and essential oils of Curcuma aeruginosa, Curcuma mangga, and Zingiber cassumunar from Malaysia, Asian Pacific Journal of Tropical Medicine, 5, 3, (2012) 202-209 http://dx.doi.org/10.1016/S1995-7645(12)60025-X

[6] Dyah Iswantini, Rhoito Froista Silitonga, Elizabeth Martatilofa, Latifah Kosim Darusman, Zingiber cassumunar, Guazuma ulmifolia, and Murraya paniculata Extracts as Antiobesity: In Vitro Inhibitory Effect on Pancreatic Lipase Activity, HAYATI Journal of Biosciences, 18, 1, (2011) 6-10 http://dx.doi.org/10.4308/hjb.18.1.6

[7] Supinya Tewtrakul, Sanan Subhadhirasakul, Antiallergic activity of some selected plants in the Zingiberaceae family, Journal of Ethnopharmacology, 109, 3, (2007) 535-538 http://dx.doi.org/10.1016/j.jep.2006.08.010

[8] M. Habsah, M. Amran, M. M. Mackeen, N. H. Lajis, H. Kikuzaki, N. Nakatani, A. A. Rahman, Ghafar, A. M. Ali, Screening of Zingiberaceae extracts for antimicrobial and antioxidant activities, Journal of Ethnopharmacology, $72, \quad 3, \quad(2000) \quad 403-410$ http://dx.doi.org/10.1016/S0378-8741(00)00223-3.

[9] Sofnie Marusin Chairul, Phagocytosis effectivity test of phenylbutenoid compounds isolated from Bangle (Zingiber cassumunar Roxb.) Rhizome, Biodiversitas, $10,1,(2009)$ 40-43

[10] Marsden S. Blois, Antioxidant Determinations by the Use of a Stable Free Radical, Nature, 181, (1958) 1199 http://dx.doi.org/10.1038/1811199ao

[11] KR Markham, Cara Mengidentifikasi Flavonoid, ITB, Bandung, 1988. 